\begin{tabular}{|c|c|c|}
\hline 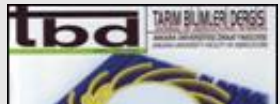 & $\begin{array}{l}\text { Tarım Bilimleri Dergisi } \\
\text { Tar. Bil. Der. }\end{array}$ & Journal of Agricultural Sciences \\
\hline & $\begin{array}{c}\text { Dergi web sayfası: } \\
\text { www.agri.ankara.edu.tr/dergi }\end{array}$ & $\begin{array}{l}\text { Journal homepage: } \\
\text { www.agri.ankara.edu.tr/journal }\end{array}$ \\
\hline
\end{tabular}

\title{
Determination of the Hydraulic Properties of a Flat Type Drip Emitter using Computational Fluid Dynamics
}

\author{
Vedat DEMİa ${ }^{a}$, Hüseyin YÜRDEM ${ }^{a}$, Arzu YAZGI ${ }^{a}$, Tuncay GÜNHAN ${ }^{a}$

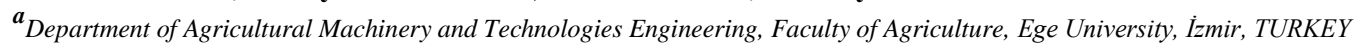

\author{
ARTICLE INFO \\ Research Article \\ Corresponding Author: Vedat DEMIR, E-mail: vedat.demir@ege.edu.tr, Tel: +90 (232) 3112824 \\ Received: 5 December 2018, Received in Revised Form: 28 February 2019, Accepted: 04 April 2019
}

\section{AUTHORS ORCID ID}

(Vedat DEMIR: 0000-0001-8341-9672), (Hüseyin YÜRDEM: 0000-0003-2711-2697), (Arzu YAZGI: 0000-0003-0141-8882), (Tuncay GÜNHAN: 0000-0003-4462-2410)

\section{ABSTRACT}

The objective of this study was to determine the hydraulic properties of a flat type emitter using Computational Fluid Dynamics with different turbulence models and model options. In addition, it is aimed to investigate the effects of the emitter hydraulic properties on the design when the same emitter is used in drip irrigation pipes with different wall thicknesses. The lowest mean percentage deviation between the measured flow rates and the calculated flow rates with turbulence models was found as $0.70 \%$ and $0.74 \%$ in the SST $k-\omega$ and Stress-Omega RSM turbulence model for the wall thickness of $0.25 \mathrm{~mm}$ pipe, respectively. Also, the mean percentage deviation for the laminar turbulence model was found to be $-1.01 \%$. The minimum MAE $\left(0.021 \mathrm{~L} \mathrm{~h}^{-1}\right)$ and $\operatorname{RMSE}\left(0.028 \mathrm{~L} \mathrm{~h}^{-1}\right)$ values were found in the SST $k$ - $\omega$ low-Re corr. turbulence model and the minimum MAPE $(1.068 \%)$ was found in the laminar turbulence model.

Keywords: Turbulence models; Emitter design; CFD

(C) Ankara Üniversitesi Ziraat Fakültesi

\section{Introduction}

Drip emitters are used to dissipate pressure in the lateral line and discharge the water in drip irrigation system. This dissipation pressure in the emitter is generally carried out by labyrinth channels with narrow and long flow paths. The geometric structure (tortuous, orifice etc. flow path) and dimensions (channel with and depth, dentation angle, spacing, and height) of the labyrinth channels directly affect the hydraulic characteristics of the emitter. Decreasing the flow path dimensions makes it easier to reduce pressure dissipation, but increases the risk of clogging.

An important parameter in the emitter design is to determine the emitter flow rate depending on the operating pressure and the geometry of the emitter flow path, and the relationship between them can be described as follows (Von Bernuth \& Solomon 1986).

$q=k H^{x}$

Where; $q$, emitter flow rate $\left(\mathrm{L} \mathrm{h}^{-1}\right) ; H$, emitter operating pressure $(\mathrm{kPa}) ; k$, emitter flow coefficient $\left(\mathrm{L} \mathrm{h}^{-1}\right.$ $\left.\mathrm{kPa}^{-\mathrm{x}}\right) ; x$, emitter flow exponent in dimensionless. The value of the coefficient of $k$ in Equation 1 depends on the 
physical dimensions of the water passage paths in the emitter. The value of $x$ characterizes the emitter's flow regime.

Conventionally the development process of a new emitter needs time-consuming and high-cost operations. Nowadays products can be designed by sophisticated visible models. It is also possible to perform performance analyzes such as kinematics, fluid dynamics, production processes in the 3D design in the computer. Thus, it is possible to obtain the products at a lower cost, with as possible higher performance and in a shorter time.

The flow regime for the geometry of water flow channels of a drip emitter can be defined by the dimensionless Reynolds number for a Newtonian fluid (Munson et al 2006).

$R e=\frac{V D_{h}}{v}$

Where; $V=q / A_{c s}$, average velocity of flow in the cross-sectional area in $\mathrm{m} \mathrm{s}^{-1} ; q$, emitter flow rate in $\left(\mathrm{L} \mathrm{h}^{-1}\right)$; $A_{c s}=w \cdot d$, cross-sectional area of emitter flow path $\left(\mathrm{m}^{2}\right) ; w$ and $d$, minimum width and depth of the emitter channels $(\mathrm{m}) ; D_{h}=4 w d / 2(w+d)$, hydraulic diameter for a rectangular channel $(\mathrm{m}) ; v$, kinematic viscosity of fluid $\left(\mathrm{m}^{2} \mathrm{~s}^{-1}\right)$ (Munson et al 2006; Wei et al 2006; Li et al 2006; Zhang et al 2016).

In the past studies, the Reynolds numbers were generally found between 100-1500 in the laminar flow region $(\operatorname{Re}<2000)$ due to the flow path of the emitter was relatively small and the flow rates were quite low. However, numerous researchers had indicated that the flow in this region was through the laminar to turbulence or turbulence due to the flow path in the emitter was tortuous and relatively small cross-section channels. Therefore, they stated that turbulence models would be more compatible for Computational Fluid Dynamics (CFD) applications (Wei et al 2006; Dazhuang et al 2007; Zhang et al 2007; Li et al 2008; Cicconi \& Raffaeli 2009; Liu et al 2009; Philipova et al 2009; Wu et al 2013).

Palau-Salvador et al (2004) found 95\% compatible results between the experimental and simulation values for emitters with labyrinth flow channel in CFD analysis. Wang et al (2006) stated that the difference between experimental and calculated results was less than $2 \%$ in terms of velocity and pressure distributions in emitter for standard $k-\varepsilon$ turbulence model with standard wall function. Philipova et al (2009) and Wei et al (2006) showed that the pressure-flow relationships could be found with less than $4 \%$ error using the same turbulence model in labyrinth flow channels for the emitter.

In the CFD studies conducted on this subject, solutions were generally performed using selected a turbulence model. However, solution methods and mesh structure considered in the solution were not clearly indicated. Furthermore, there were no evaluations in the literature regarding the contribution of different turbulence models and wall applications to the solution. The objective of this study was to determine the hydraulic properties of a flat type emitter using CFD techniques with different turbulence models and model options, and presentation of the approach that gives the closest solution by comparing with experimental data. In addition, it is aimed to investigate the effects of the emitter hydraulic properties on the design when the same emitter is used in drip irrigation pipes with different wall thicknesses.

\section{Material and Methods}

\subsection{Experimental studies}

Drip irrigation pipes equipped with flat type drip emitters were used in this study. Nominal flow rate of selected drip emitter was $1.6 \mathrm{~L} \mathrm{~h}^{-1}$ at $100 \mathrm{kPa}$ of operating pressure. The pipe wall thicknesses were $0.15 \mathrm{~mm}(6 \mathrm{mil})$, $0.20 \mathrm{~mm}(8 \mathrm{mil})$ and $0.25 \mathrm{~mm}(10 \mathrm{mil})$. The general view and dimensions of the tested drip emitter are shown in Figure 1.

The drip irrigation laterals were placed horizontally on the test stand presented in Figure 2 (Korukçu 1980; Mizyed \& Kruse 1989). Water was supplied to the system passing through the disc filter by using a pump, and the operating pressures of $50,80,100,120,150,200$ and $250 \mathrm{kPa}$ were adjusted by the control valves at the pump 
outlet. The pressure values were measured by a digital manometer (Keller LEO1, Switzerland) having a precision of $<0.1 \%$ of the full scale. The flow rates of a total 30 of emitters in each drip irrigation pipes were measured using $1000 \mathrm{ml}$ graduated cylinders at the different operating pressures (Bralts \& Wu 1979; Mizyed \& Kruse 1989).
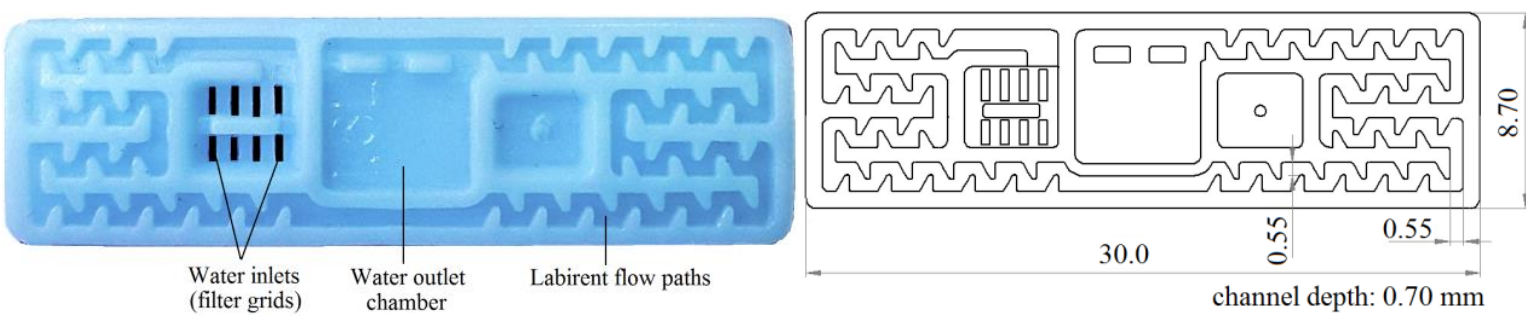

Figure 1- General view of the flat type integrated in-line drip emitter used in study
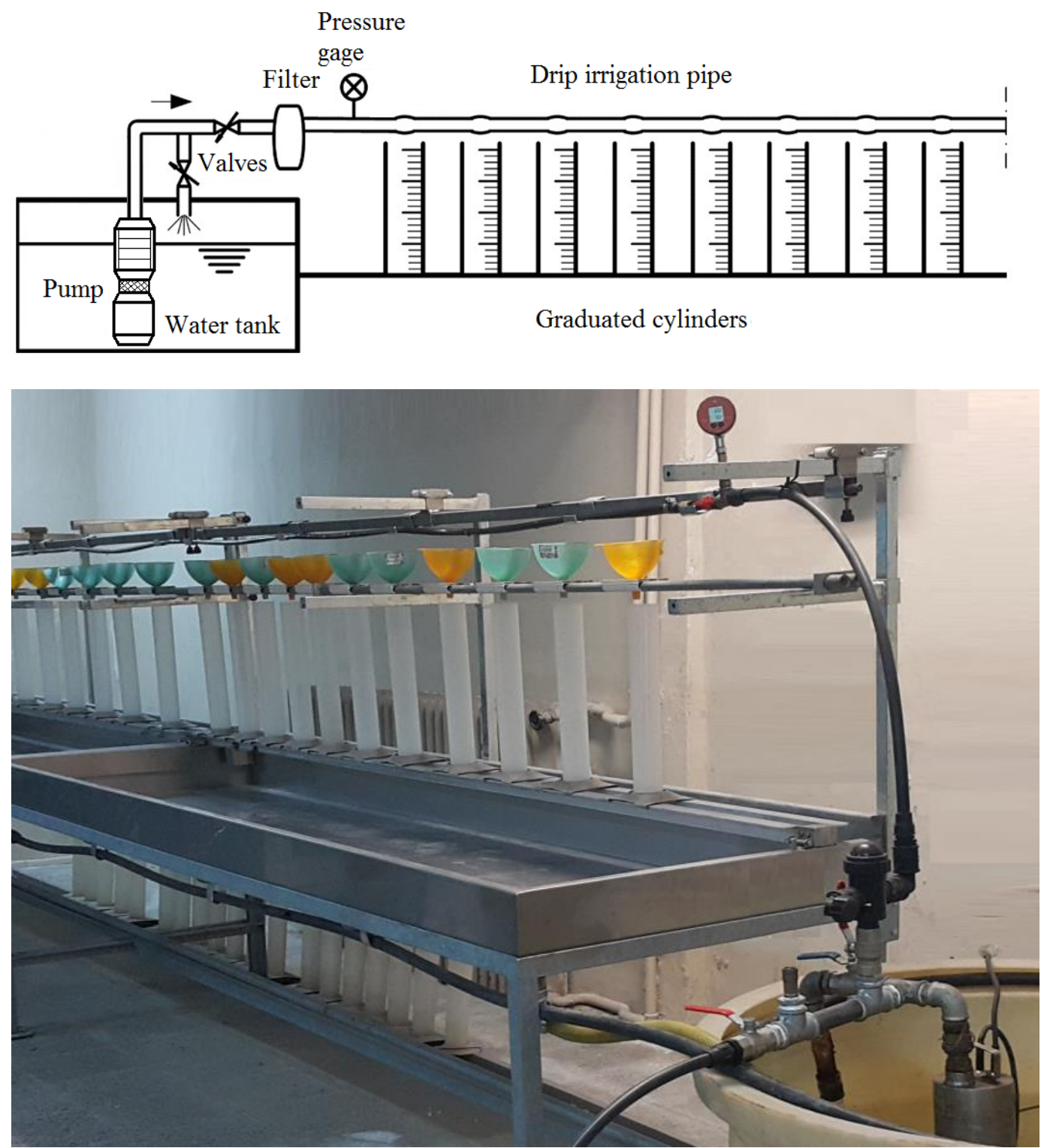

Figure 2. Schematics and experimental view of test stand 


\subsection{CFD analysis studies}

The flow analysis of emitter water flow channels were performed using commercial CFD software ANSYS Fluent 17.2 (ANSYS 2016).

\subsubsection{Geometrical model and mesh generation}

The geometrical models for drip emitter used in the study were created using ANSYS Design Modeler software. After created geometrical models, the mesh structures for water flow channels in drip emitter were formed using ANSYS Meshing software (Figure 3). The minimum dimension of one grid in mesh structure was selected as a $0.1 \mathrm{~mm}$. The number of nodes and elements in this mesh structure were more than $3.5 \times 10^{5}$ and $2.2 \times 10^{5}$ respectively.

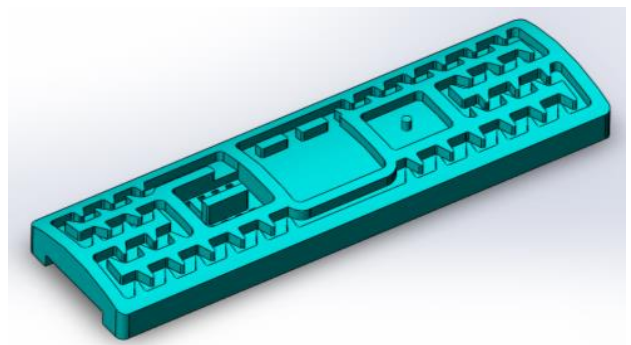

Drip emitter

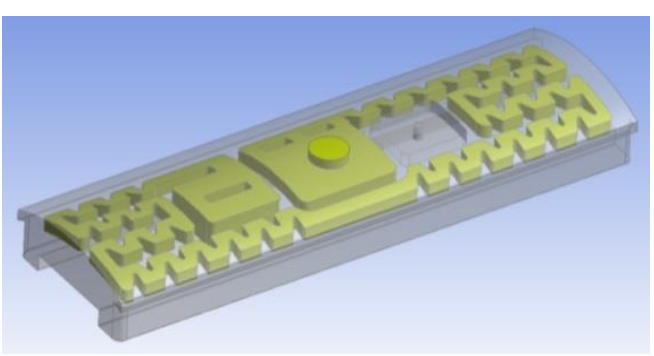

Water in flow channels in drip emitter

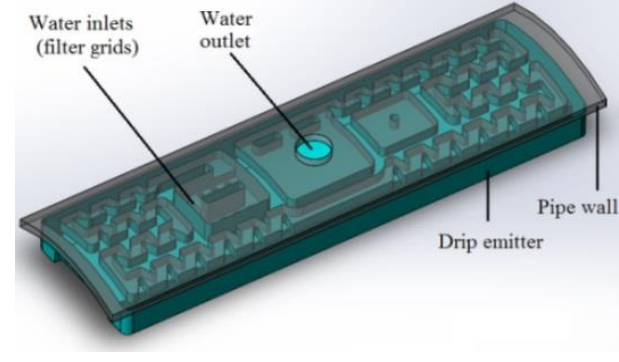

Pipe wall and drip emitter

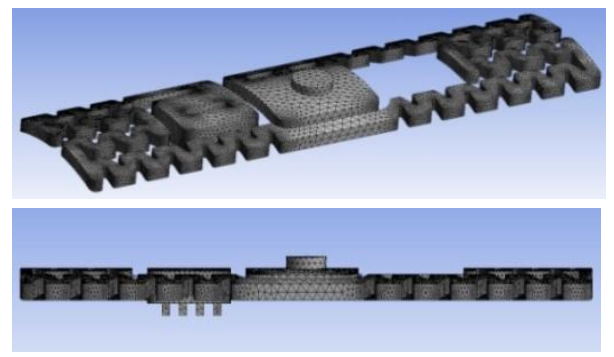

Mesh of the water in flow channels

Figure 3- Geometry of the drip emitter and mesh of the water flow channels

\subsubsection{Mathematical model}

The flow motion of the fluid can be described by the mass and momentum conservation equations. In the Newtonian, incompressible and steady-state flow condition, the density of fluid is the constant, and the conservation of mass or continuity equation is defined as:

$\nabla \cdot \mathrm{v}=\mathrm{O}$

Similarly, an incompressible Newtonian fluid with constant viscosity, in vector notation of the Navier-Stokes equations is defined as:

$\rho\left(\frac{\partial \mathrm{v}}{\partial t}+(\mathrm{v} \cdot \nabla) \mathrm{v}\right)=-\nabla p+\rho g+\mu \nabla^{2} \mathrm{v}$

In equations; $\nabla$ is the vector operator $(\nabla=\partial / \partial x+\partial / \partial y+\partial / \partial z)$; $\mathrm{v}$, mean velocity vector $\left(\mathrm{m} \mathrm{s}^{-1}\right) ; \rho$, density of fluid $\left(\mathrm{kg} \mathrm{m}^{-3}\right) ; p$, static pressure $(\mathrm{Pa}) ; \mathrm{g}$, acceleration of gravity vector $\left(\mathrm{m} \mathrm{s}^{-2}\right) ; \mu$, viscosity of fluid (Pa s) (Versteeg \& Malalasekera 1995; Munson et al 2006; ANSYS 2016). 
For the numerical analysis of Navier-Stokes equations in turbulence flow, the approach is called as Reynolds Averaged Navier Stokes (RANS) equations for the variation of fluctuating velocity, pressure, and other scalar quantities considering take the time-average. Various turbulence models are used in the RANS approach to analyzing the Reynolds stress tensor term appropriately, taking into account the effects of turbulence.

In this study, realizable $k$ - $\varepsilon$ turbulence model with enhanced wall treatment, SST $k$ - $\omega$ turbulence model with low-Re corrections and production limiter options and Stress-Omega Reynolds Stress Model (RSM) with lowRe corrections and shear flow corrections options were considered for CFD analysis.

\subsubsection{Boundary conditions and solution methods}

In ANSYS Fluent analysis; the fluid was chosen as water, it was assumed to be a steady, incompressible, viscous and non-gravity effect. Inlet boundary condition was set to be operating pressures $(50,80,100,120,150,200$ and $250 \mathrm{kPa}$ ) and outlet boundary condition was assumed to $0 \mathrm{kPa}$ (atmospheric pressure). Hydraulic diameter of the flow channels was taken into account in Reynolds number calculations. Surface roughness height was not considered because of the quite low roughness height of the plastic producing material of the emitters. Simple algorithms and Second Order Discretization Schemes were used in all solutions. In the study, a limit value of 500 iterations was applied for the stability of the solution. The solution convergence accuracy was accepted to be $1 \times 10^{-5}$.

\subsection{Statistical analysis}

The mean absolute error (MAE), the root mean square error (RMSE) and the mean absolute percentage error (MAPE) were used to compare the differences between the experimental flow rate data and the predicted data using CFD models (Willmott \& Matsuura 2005; Ding et al 2017). As it is known, the lowest values of these comparison criterion given below represent the highest model prediction.

$$
\begin{aligned}
& \text { MAE }=\frac{1}{n} \sum_{i=1}^{n}\left|q_{i, \text { Exp }}-q_{i, C F D}\right| \\
& \text { RMSE }=\left\lceil\frac{1}{n} \sum_{\mathrm{i}=1}^{n}\left(\mathrm{q}_{i, C F D}-q_{i, E x p}\right)^{2}\right]^{1 / 2} \\
& \text { MAPE }=\frac{100}{n} \sum_{i=1}^{n}\left|\frac{q_{i, E x p}-q_{i, C F D}}{q_{i, E x p}}\right|
\end{aligned}
$$

Where; $q_{i, E x p}$ is experimental and $q_{i, C F D}$ is the simulation values, $n$ is the number of data.

\section{Results and Discussion}

Drip emitter parameters and manufacturing variations depending on the measuring results for drip irrigation pipes with different wall thickness are given in Table 1. Also, calculated emitter flow rates depending on the inlet pressure using the CFD simulation models considered in the study, and the percentage deviation values according to the measured and calculated flow rates were shown in the same table.

The emitter flow exponent $(x)$ values were found to be very close to 0.5 (Table 1 ). Therefore, it can be said that the emitter flow regime is fully turbulence (Von Bernuth \& Solomon 1986). The emitter manufacturing variations values were found excellent according to the classification of ASAE standards for all wall thicknesses. It can be said that all emitter are manufactured quite close to each other in that production technology (Von Bernuth \& Solomon 1986).

The emitter flow rate was found as $1.655 \mathrm{~L} \mathrm{~h}^{-1}$ for $0.25 \mathrm{~mm}$ pipe wall thickness at the nominal working pressure of $100 \mathrm{kPa}$ for a considered emitter with the nominal flow rate of $1.6 \mathrm{~L} \mathrm{~h}^{-1}$. These results indicated that the emitter was designed for a pipe wall thickness of $0.25 \mathrm{~mm}$. It was determined that the emitter flow increased 
when the pipe wall thickness of the drip irrigation pipe decreased (Table 1). For example, it was found that the emitter flow rate increased by $3.2 \%$ and $5.14 \%$ at the nominal working pressure of $100 \mathrm{kPa}$ for the pipes manufactured as $0.20 \mathrm{~mm}$ and $0.15 \mathrm{~mm}$ of pipe wall thickness instead of $0.25 \mathrm{~mm}$. Cicconi \& Raffaeli (2009) stated that the emitter flow rate in three different drip irrigation pipes increased from $4.7 \%$ to $12.2 \%$ when the pipe thickness decreased from $1.2 \mathrm{~mm}$ to $1.0 \mathrm{~mm}$. The results were similar. This variation in flow rates may also be explained by the increase in emitter flow cross-sectional area due to the reduction of overlap of the emitter with the plastic material during the connection of the pipe and the drip emitter in the extruder line. In addition, it appears that the emitter flow cross-sectional area have more influence due to the increase in pressure on the material with less pipe wall thickness.

CFD simulation studies are generally carried out by assuming that the water flow path is constant and does not change by external factors. However, the experimental results showed that the change in pipe wall thickness had an effect on the flow rate due to the changes emitter flow path. Therefore, constant flow rates were found for each considered turbulence model. The comparison of the flow rates calculated with CFD and measured according to each pipe wall thickness is given as percentage deviation in Table 1. In addition, a comparison of the flow rates calculated with the turbulence models and measured at different working pressures for the pipe wall thickness of $0.25 \mathrm{~mm}$ are given in Figure 4 .

Table 1- The results for drip emitter hydraulic properties and percentage deviation of drip emitter flow rates

\begin{tabular}{|c|c|c|c|c|c|c|c|c|c|c|c|c|c|}
\hline \multirow{3}{*}{$\begin{array}{c}\text { Pipe } \\
\text { wall } \\
\text { thickness }\end{array}$} & \multirow{2}{*}{\multicolumn{2}{|c|}{$\begin{array}{c}\text { Emitter } \\
\text { parameters }\end{array}$}} & \multirow{3}{*}{ 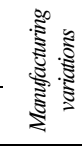 } & \multirow{3}{*}{$\begin{array}{l}\text { Operating } \\
\text { pressure }\end{array}$} & \multirow{3}{*}{$\begin{array}{l}\text { Experimental } \\
\text { flow rate }\end{array}$} & \multicolumn{8}{|c|}{ CFD simulation models } \\
\hline & & & & & & \multirow{2}{*}{\multicolumn{2}{|c|}{ Laminar }} & \multirow{2}{*}{\multicolumn{2}{|c|}{$\begin{array}{c}\text { SST k- } \omega \\
\text { low-Re corr. }\end{array}$}} & \multirow{2}{*}{\multicolumn{2}{|c|}{$\begin{array}{l}\text { Realizable } k-\varepsilon \\
\text { enhanced wall }\end{array}$}} & \multirow{2}{*}{\multicolumn{2}{|c|}{$\begin{array}{l}\text { Stress-Omega RSM } \\
\text { low-Re corr. }\end{array}$}} \\
\hline & Flow & Flow & & & & & & & & & & & \\
\hline$e$ & $k$ & $x$ & $V_{m}{ }^{*}$ & $H$ & $q_{e p p}$ & $\begin{array}{c}\text { Predicted } \\
\text { flow rate, } q_{\text {pre }}\end{array}$ & $\begin{array}{l}\text { Percentage } \\
\text { deviation }^{* *}\end{array}$ & $\begin{array}{c}\text { Predicted } \\
\text { flow rate, } q_{\text {pre }}\end{array}$ & $\begin{array}{l}\text { Percentage } \\
\text { deviation }\end{array}$ & $\begin{array}{c}\text { Predicted } \\
\text { flow rate, } q_{p r e}\end{array}$ & $\begin{array}{l}\text { Percentage } \\
\text { deviation }\end{array}$ & $\begin{array}{c}\text { Predicted } \\
\text { flow rate, } q_{p r e}\end{array}$ & $\begin{array}{l}\text { Percentage } \\
\text { deviation }\end{array}$ \\
\hline$(\mathrm{mm})$ & $\begin{array}{l}\left(L h^{-1}\right. \\
\left.k P a^{-x}\right)\end{array}$ & - & - & $(k P a)$ & $\left(L h^{-1}\right)$ & $\left(L h^{-1}\right)$ & (\%) & $\left(L h^{-1}\right)$ & (\%) & $\left(L h^{-1}\right)$ & (\%) & $\left(L h^{-1}\right)$ & (\%) \\
\hline \multirow{8}{*}{$\begin{array}{c}0.25 \\
\mathrm{~mm} \\
(10 \mathrm{mil})\end{array}$} & \multirow{8}{*}{0.1555} & \multirow{8}{*}{0.5127} & \multirow{8}{*}{0.0191} & 50 & 1.150 & 1.150 & 0.00 & 1.127 & 2.00 & 1.163 & -1.13 & 1.117 & 2.87 \\
\hline & & & & 80 & 1.483 & 1.481 & 0.13 & 1.438 & 3.03 & 1.512 & -1.96 & 1.440 & 2.90 \\
\hline & & & & 100 & 1.655 & 1.656 & -0.06 & 1.631 & 1.45 & 1.712 & -3.44 & 1.614 & 2.48 \\
\hline & & & & 120 & 1.798 & 1.815 & -0.95 & 1.795 & 0.17 & 1.891 & -5.17 & 1.791 & 0.39 \\
\hline & & & & 150 & 2.033 & 2.057 & -1.18 & 2.031 & 0.10 & 2.135 & -5.02 & 2.037 & -0.20 \\
\hline & & & & 200 & 2.363 & 2.395 & -1.35 & 2.364 & -0.04 & 2.499 & -5.76 & 2.394 & -1.31 \\
\hline & & & & 250 & 2.628 & 2.724 & -3.65 & 2.675 & -1.79 & 2.822 & -7.38 & 2.679 & -1.94 \\
\hline & & & & Avg. & - & - & -1.01 & - & 0.70 & - & -4.27 & - & 0.74 \\
\hline \multirow{8}{*}{$\begin{array}{c}0.20 \\
\mathrm{~mm} \\
(8 \mathrm{mil})\end{array}$} & \multirow{8}{*}{0.1594} & \multirow{8}{*}{0.5144} & \multirow{8}{*}{0.0239} & 50 & 1.190 & 1.150 & 3.36 & 1.127 & 5.29 & 1.163 & 2.27 & 1.117 & 6.13 \\
\hline & & & & 80 & 1.525 & 1.481 & 2.89 & 1.438 & 5.70 & 1.512 & 0.85 & 1.440 & 5.57 \\
\hline & & & & 100 & 1.708 & 1.656 & 3.04 & 1.631 & 4.51 & 1.712 & -0.23 & 1.614 & 5.50 \\
\hline & & & & 120 & 1.870 & 1.815 & 2.94 & 1.795 & 4.01 & 1.891 & -1.12 & 1.791 & 4.22 \\
\hline & & & & 150 & 2.085 & 2.057 & 1.34 & 2.031 & 2.59 & 2.135 & -2.40 & 2.037 & 2.30 \\
\hline & & & & 200 & 2.440 & 2.395 & 1.84 & 2.364 & 3.11 & 2.499 & -2.42 & 2.394 & 1.89 \\
\hline & & & & 250 & 2.730 & 2.724 & 0.22 & 2.675 & 2.01 & 2.822 & -3.37 & 2.679 & 1.87 \\
\hline & & & & Avg. & - & - & 2.23 & - & 3.89 & - & -0.92 & - & 3.93 \\
\hline \multirow{8}{*}{$\begin{array}{c}0.15 \\
\mathrm{~mm} \\
(6 \mathrm{mil})\end{array}$} & \multirow{8}{*}{0.1986} & \multirow{8}{*}{0.4734} & \multirow{8}{*}{0.0235} & 50 & 1.265 & 1.150 & 9.09 & 1.127 & 10.91 & 1.163 & 8.06 & 1.117 & 11.70 \\
\hline & & & & 80 & 1.605 & 1.481 & 7.73 & 1.438 & 10.40 & 1.512 & 5.79 & 1.440 & 10.28 \\
\hline & & & & 100 & 1.740 & 1.656 & 4.83 & 1.631 & 6.26 & 1.712 & 1.61 & 1.614 & 7.24 \\
\hline & & & & 120 & 1.900 & 1.815 & 4.47 & 1.795 & 5.53 & 1.891 & 0.47 & 1.791 & 5.74 \\
\hline & & & & 150 & 2.115 & 2.057 & 2.74 & 2.031 & 3.97 & 2.135 & -0.95 & 2.037 & 3.69 \\
\hline & & & & 200 & 2.465 & 2.395 & 2.84 & 2.364 & 4.10 & 2.499 & -1.38 & 2.394 & 2.88 \\
\hline & & & & 250 & $-^{* * * *}$ & 2.724 & - & 2.675 & - & 2.822 & - & 2.679 & - \\
\hline & & & & Avg. & - & - & 5.28 & - & 6.86 & - & 2.27 & - & 6.92 \\
\hline
\end{tabular}

${ }^{*}, V_{m}=S_{q} / q_{\text {avg }} ; S_{q}$ is the standard deviation; $q_{\text {avg }}$ is the mean drip emitter flow rate; ${ }^{* *}, 100 \cdot\left(q_{e v}-q_{p r e}\right) q_{e q} ;{ }^{* * *}$, the experimental data could not be measured because this pressure was higher than the strength of the pipe at this wall thickness

It was seen that the calculated flow rates with considered turbulence models except for realizable $k$ - $\varepsilon$ turbulence model with enhanced wall treatment were quite close to the measured flow rates for pipe wall thickness of $0.25 \mathrm{~mm}$ (Figure 4). Furthermore, as can be seen from Table 1, the lowest mean percentage deviation between the measured and the calculated flow rates was found as $0.70 \%$ in the SST $k$ - $\omega$ turbulence model for the pipe wall thickness of $0.25 \mathrm{~mm}$. Moreover, another close mean percentage deviation was found as 
$0.74 \%$ with the Stress-Omega RSM. The mean percentage deviation for the laminar turbulence model, which is accepted as a model with an easy and fast solution, was found to be $-1.01 \%$. This results found in the study were less than the percentage deviations of 2 to $5 \%$ found by various researchers in simulation studies (Palau-Salvador et al 2004; Wang et al 2006; Wei et al 2006; Zhang et al 2007; Cicconi \& Raffaeli 2009; Philipova et al 2009; Wu et al 2013). Cicconi \& Raffaeli (2009) stated that there were differences from 8.5 to $12.8 \%$ in the flow rates for the experimental and the $k-\varepsilon$ turbulence models depending on pipe wall thickness and emitter flow channel depth for the flat drip at $100 \mathrm{kPa}$ inlet pressure. These results clearly show that the emitter should be designed considering the pipe wall thickness.

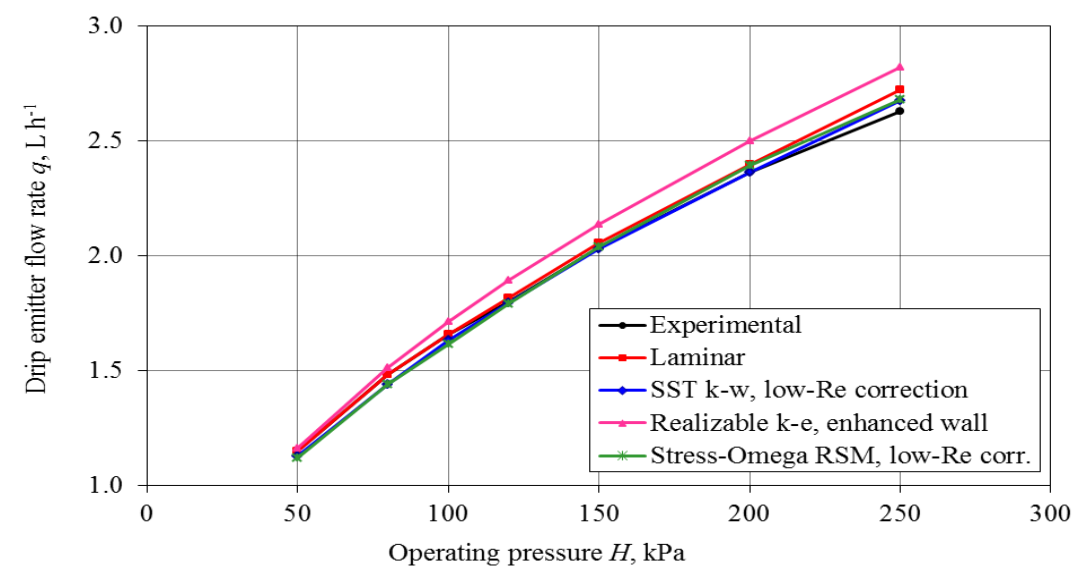

Figure 4- Comparison of the operating pressure and flow rate relationship of the drip emitter for experimental and CFD models for $0.25 \mathrm{~mm}$ pipe wall thickness

The MAE, the RMSE and the MAPE were calculated to compare the performances of considered CFD models for $0.25 \mathrm{~mm}$ pipe wall thickness and the results were given in Table 2. In addition to the comparison criterion, to show the harmony between the experimental and predicted flow rates for four CFD turbulence models is given in Figure 5.

Table 2- The MAE, RMSE and MAPE results for all simulation models for pipe wall thickness of $0.25 \mathrm{~mm}$

\begin{tabular}{lccc}
\hline CFD Models & $\begin{array}{c}\text { Mean absolute } \\
\text { error } \\
M A E\left(L h^{-1}\right)\end{array}$ & $\begin{array}{c}\text { Root mean } \\
\text { square error } \\
\text { RMSE }\left(L h^{-1}\right)\end{array}$ & $\begin{array}{c}\text { Mean absolute } \\
\text { percentage error } \\
\text { MAPE }(\%)\end{array}$ \\
\hline Laminar & 0.025 & 0.040 & 1.068 \\
SST $k$ - $\omega$ low-Re corr. & 0.021 & 0.028 & 1.224 \\
Realizable $k$ - $\varepsilon$ enhanced wall & 0.089 & 0.107 & 4.281 \\
Stress-Omega RSM low-Re corr. & 0.030 & 0.034 & 1.723 \\
\hline
\end{tabular}
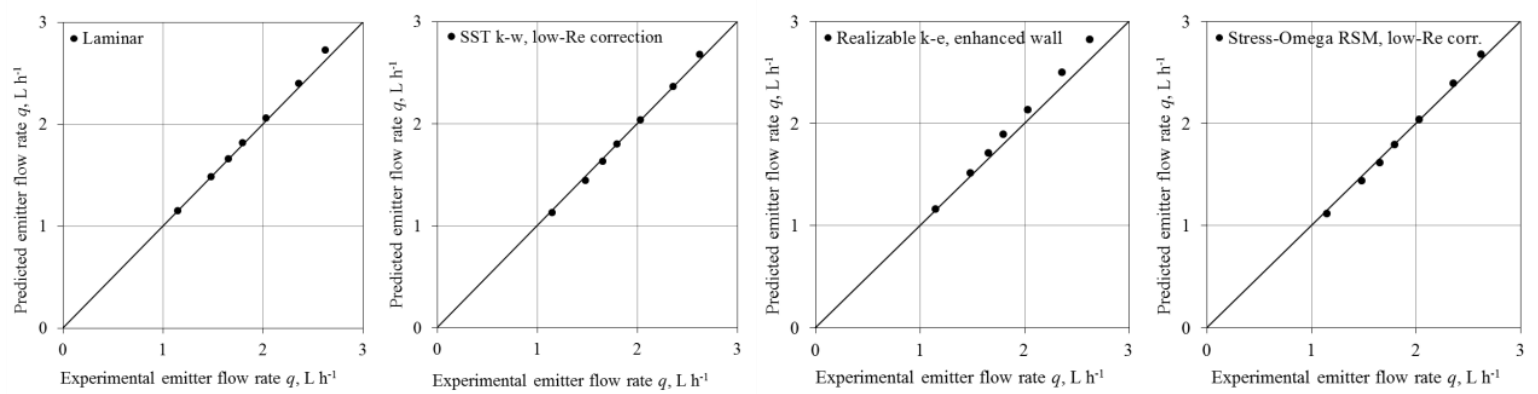

Figure 5- Comparison of the experimental and predicted drip emitter flow rate for the considered turbulence models 
As seen in Table 2, among those CFD simulation models, the minimum MAE $\left(0.021 \mathrm{~L} \mathrm{~h}^{-1}\right)$ and RMSE $\left(0.028 \mathrm{~L} \mathrm{~h}^{-1}\right)$ values were found in the SST $k$ - $\omega$ low-Re corr. turbulence model and the minimum MAPE $(1.068 \%)$ was found in the laminar turbulence model. These results indicated that the flow rate could be calculated with the SST $k$ - $\omega$ low-Re correction and the laminar turbulence models with a very low error compared to the measured emitter flow rate, and the emitter design could be done quickly and easily using simulation method (Figure 5).

The flow characteristics of the emitter flow channels were also investigated in the study. For this purpose, the flow coefficient $(k)$ and the flow exponent $(x)$ were calculated with the considered CFD simulation models. The results were also compared with the experimental data for the pipe wall thickness of $0.25 \mathrm{~mm}$ (Table 3 ). In addition, the flow velocities and the Reynolds numbers at the lowest and highest emitter flow rates in the minimum flow cross-section area of the emitter were determined. These results are given in Table 3.

Table 3- Comparison of the emitter properties, and range of flow velocity, Reynolds numbers for experimental data and different CFD simulation models for pipe wall thickness of $0.25 \mathrm{~mm}$

\begin{tabular}{|c|c|c|c|c|}
\hline \multirow{3}{*}{ Data source } & \multicolumn{2}{|c|}{ Emitter parameters } & \multirow{2}{*}{$\begin{array}{c}\text { Range of } \\
\text { flow velocity }\end{array}$} & \multirow{2}{*}{$\begin{array}{c}\text { Range of } \\
\text { Reynolds } \\
\text { number }\end{array}$} \\
\hline & Flow coefficient & Flow exponent & & \\
\hline & $k\left(L h^{-1} k P a^{-x}\right)$ & $x$ & $V\left(m s^{-1}\right)$ & $R_{e}$ \\
\hline Experimental & 0.1555 & 0.5127 & $0.83-1.90$ & $506-1156$ \\
\hline Laminar & 0.1426 & 0.5329 & $0.83-1.97$ & $505-1198$ \\
\hline SST $k$ - $\omega$, low-Re correction & 0.1366 & 0.5384 & $0.81-1.93$ & $495-1177$ \\
\hline Realizable $k-\varepsilon$, enhanced wall & 0.1355 & 0.5503 & $0.84-2.04$ & $512-1242$ \\
\hline Stress-Omega RSM, low-Re corr. & 0.1306 & 0.5477 & $0.81-1.93$ & $492-1179$ \\
\hline
\end{tabular}

When the $\mathrm{k}$ and $\mathrm{x}$ values, which denote the emitter dimensions and flow properties, were analyzed, it was found that the results of the laminar and SST $k-\omega$ Low-Re corr. models were the closest to the experimental values. The Reynold numbers were calculated depending on the flow rate of the emitter, and found between 500 and 1250, approximately. These values were found in harmonious with the other researches (Li et al 2006; Wei et al 2006; Dazhuang et al 2007; Zhang et al 2007; Zhang et al 2016).

The flow velocity distributions at the different input velocities and the pressure distributions for laminar and SST $k-\omega$ Low-Re corr. models were examined and the results are given in Figure 6 . There was no significant difference observed between the two models in terms of pressure and flow velocity distributions. It was observed that the pressure might be reduced to the desired value in the flow channels.

Laminar model

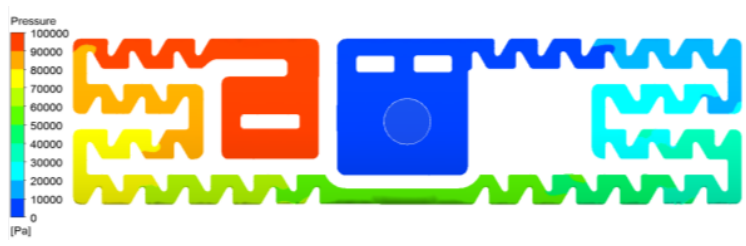

Pressure distribituon

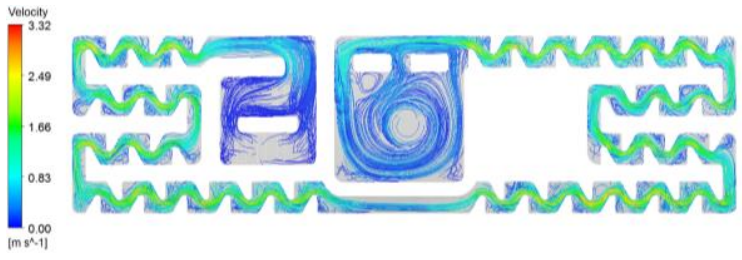

Flow velocity distribution
SST $k-\omega$ Low-Re corr. model
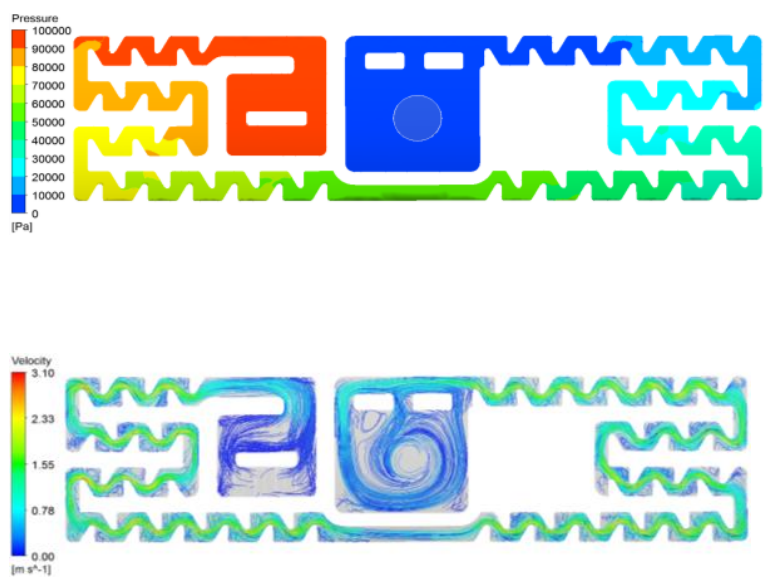

Figure 6- Pressure and flow velocity distributions in emitter flow channels 
When flow velocity distributions were analyzed, it was seen that high flow velocities such as $3 \mathrm{~m} \mathrm{~s}^{-1}$ occurred depending on the cross-section in the flow channel. The flow velocity decreased considerably on the walls of the flow channels, and generally, $0.5 \mathrm{~m} \mathrm{~s}^{-1}$ and higher flow velocities occurred in the center of the channel. In the flow channels, it was seen that the flow velocity at the bottom of the sharp corners in the flow direction was very low (less than $0.5 \mathrm{~m} \mathrm{~s}^{-1}$ ), and especially in these regions vortices appeared (Figure 7). It can be said that small particles entering the drip emitter may accumulate in these regions over time due to low flow velocities and vortices in these regions may cause clogging in the emitter (Patil et al 2013). As a result, it can be said that these negative effects may be prevented by designing these zones with a slightly rounded rather than sharp edges of the water flow path.
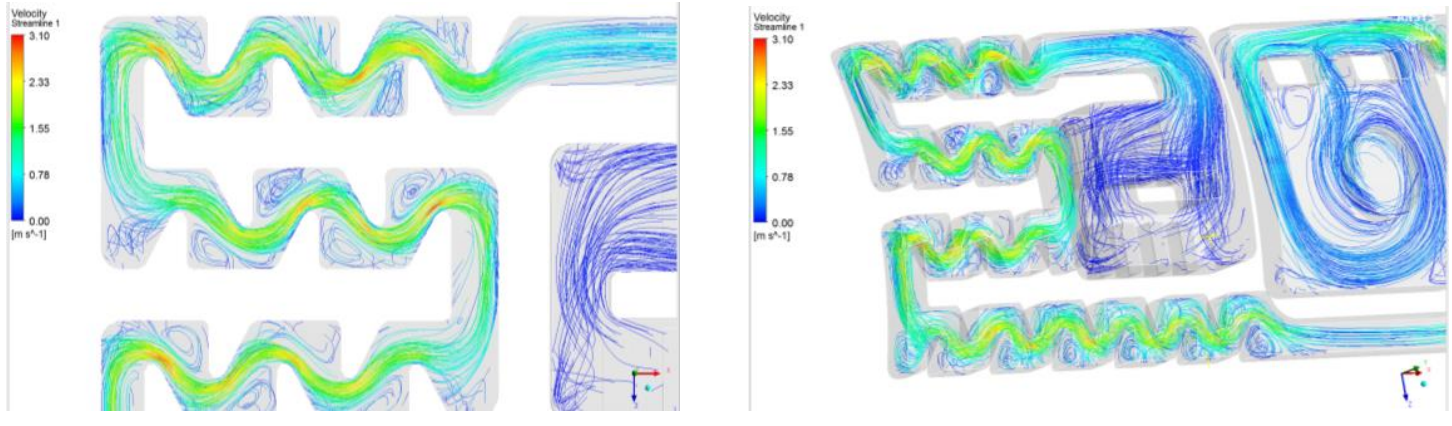

Figure 7- The details of the velocity distributions in emitter flow channels for SST $k$ - $\omega$ model

\section{Conclusions}

The following points were concluded from the conducted study:

- The emitter flow rate was found as $1.655 \mathrm{~L} \mathrm{~h}^{-1}$ for $0.25 \mathrm{~mm}$ pipe wall thickness at the nominal working pressure of $100 \mathrm{kPa}$ for a considered emitter with the nominal flow rate of $1.6 \mathrm{~L} \mathrm{~h}^{-1}$.

- The lowest mean percentage deviation between the measured flow rates and the calculated flow rates with CFD turbulence models was found as $0.70 \%$ and $0.74 \%$ in the SST $k$ - $\omega$ and Stress-Omega RSM turbulence model for the wall thickness of $0.25 \mathrm{~mm}$ pipe, respectively. Also, the mean percentage deviation for the laminar turbulence model was found to be $-1.01 \%$.

- The minimum MAE $\left(0.021 \mathrm{~L} \mathrm{~h}^{-1}\right)$ and $\operatorname{RMSE}\left(0.028 \mathrm{~L} \mathrm{~h}^{-1}\right)$ values were found in the SST $k$ - $\omega$ low-Re corr. turbulence model and the minimum MAPE (1.068\%) was found in the laminar turbulence model.

It is clear from the results that, the wall thickness of the drip irrigation pipe is an important parameter on emitter flow rate. Because of this reason, this parameter should be considered in the simulation studies carried out on emitter design. In addition, the differences between the solution approaches of the CFD simulation models affect the prediction of the drip emitter flow rates. As can be seen from the results, the emitter flow rate could be predicted very closely to the experimental data with the proper choice of the wall function and the wellconfigured mesh structure. Thus, it is possible to realize designing of an emitter with using simulation methods introduced in the study, with less effort, lower cost, minimum mold revision and in a short time.

\section{References}

ANSYS (2016). Fluent Theory Guide, Release 17.2, ANSYS, Inc.

Bralts V F \& Wu I P (1979). Emitter flow variation and uniformity for drip irrigation. ASAE Paper, St Joseph, MI, USA

Cicconi P \& Raffaeli R (2009). A knowledge based approach for affordable virtual prototyping: the drip emitters test case. In: Proceedings of the $19^{\text {th }}$ CIRP Design Conference-Competitive Design, 30-31 March, Cranfield University, UK, pp. 575583 
Dazhuang Y, Peiling Y, Shumei R, Yunkai L \& Tingwu X (2007). Numerical study on flow property in dentate path of drip emitters. New Zealand Journal of Agricultural Research 50(5): 705-712

Ding C, Lam K P \& Feng W (2017). An evaluation index for cross ventilation based on CFD simulations and ventilation prediction model using machine learning algorithms. Procedia Engineering 205: 2948-2955

Korukçu A (1980). Damla Sulamasında Yan Boru Uzunluklarının Saptanması Üzerinde Bir Araştırma. Ankara Üniversitesi Ziraat Fakültesi Yayınları: 742, Bilimsel Araştırma ve İncelemeler: 432, Ankara Üniversitesi Basımevi, Ankara

Li Y K, Yang P L, Ren S M \& Xu T W (2006). Hydraulic characterizations of tortuous flow in path drip irrigation emitter. Journal of Hydrodynamics 18(4): 449-457

Li Y K, Yang P L, Xu T W, Ren S M, Lin X G, Wei R J \& Xu H B (2008). CFD and digital particle tracking to assess flow characteristics in the labyrinth flow path of a drip irrigation emitter. Irrigation Science 26: 427-438

Liu H S, Li Y K, Liu Y Z, Yang P L, Ren S M, Wei R J \& Xu H B (2009). Flow characteristics in energy dissipation units of Labyrinth path in the drip irrigation emitters with DPIV technology. Journal of Hydrodynamics 21(6): 137-145

Mizyed N \& Kruse E G (1989). Emitter discharge evaluation of subsurface trickle irrigation systems. Transactions of the ASAE 32(4): 1223-1228

Munson B R, Young D F \& Okiishi T H (2006). Fundamentals of Fluid Mechanics. 6th Edition, J. Wiley and Sons

Palau-Salvador G, Arviza-Valverde J \& Bralts V (2004). Hydraulic flow behaviour through an in-line emitter labyrinth using CFD techniques. In: Proceedings of the ASAE/CSAE Annual International Meeting, 1-4 August, Ottawa, Canada, pp. 1-8

Patil S S, Nimbalkar P T \& Joshi A (2013). Hydraulic study, Design \& Analysis of different geometries of drip irrigation emitter labyrinth, International Journal of Engineering and Advanced Technology (IJEAT) 2(5): 455-462

Philipova N, Nikolov N, Pichurov G \& Markov D (2009). A mathematical model of drip emitter discharge depending on the geometric parameters of a labyrinth channel. In: $11^{\text {th }}$ National Congress on Theoretical and Applied Mechanics, 2-5 September, Borovets, Bulgaria, pp. 1-6

Versteeg H K \& Malalasekera W (1995). An Introduction to Computational Fluid Dynamics: The Finite Volume Method. Wiley, New York

Von Bernuth R D \& Solomon K H (1986). Design principles-emitter construction (Chapter 2). In: G S Nakayama \& D A Bucks (Eds), Trickle Irrigation for Crop Production, Elsevier Science Publishers, The Netherlands, pp. 27-141

Wang W, Wang F \& Zhao F (2006). Simulation of unsteady flow in labyrinth emitter of drip irrigation system. In: Computers in Agriculture and Natural Resources, ${ }^{\text {th }}$ World Congress Conference, 24-26 July, Orlando, Florida, pp. 630-635

Wei Q, Shi Y, Dong W, Lu G \& Huang S (2006). Study on hydraulic performance of drip emitters by computational fluid dynamics. Agricultural Water Management 84(1-2): 130-136

Willmott C J \& Matsuura K (2005). Advantages of the mean absolute error (MAE) over the root mean square error (RMSE) in assessing average model performance. Climate Research 30: 79-82

Wu D, Li Y K, Liu H S, Yang P L, Sun H S \& Liu Y Z (2013). Simulation of the flow characteristics of a drip irrigation emitter with Large Eddy Methods. Mathematical and Computer Modelling 58(3-4): 497-506

Zhang J, Zhao W, Wei Z, Tang Y \& Lu B (2007). Numerical and experimental study on hydraulic performance of emitters with arc labyrinth channels. Computers and Electronics in Agriculture 56(2): 120-129

Zhang L, Wu P T, Zhu D L \& Zheng C (2016). Flow regime and head loss in a drip emitter equipped with a labyrinth channel. Journal of Hydrodynamics 28(4): 610-616 